Myagmardorj Oyunchimeg', Badrakh Burmaajav ${ }^{2}$, Altangerel Enkhjargal ${ }^{3}$, Sambuu Tsegmed', Batbaatar Suvd', Otgonbyamba Oyun-Erdene', Davaadorj Zolzaya', Demberel Otgonbayar', Dovdon-Ulzii Oyunchimeg', Lkhagvasuren Azjargal', Ganchimeg Soyombo', Khishigt Byambasuren', Baldandorj Dorjkhand', Sandag Enkh-Amgalan', Svetlana M. Malkhazova ${ }^{5}$, Byambaa Tsogtbaatar ${ }^{1}$

'National Center for Public Health, 13381 Peace Avenue 17, 3 khoroo Bayanzurkh district, Ulaanbaatar, Mongolia, email: oyunchimeg_myagmardorj@yahoo.com ${ }^{2}$ Ach Medical University, Peace Avenue-11, Songino-Khairkhan district-18, Ulaanbaatar 18080, Mongolia, email: burmaajav55@gmail.com ${ }^{3}$ Academy of Medical Professionals, Capital Tower, Khudaldaany street, 3 khoroo, Chingeltei district, Ulaanbaatar, Mongolia, email: ajargal8@gmail.com ${ }^{4}$ Institute of Geography \& Geo ecology MAS, Social Economic Division; Erkhuu street, Chingeltei district, Ulaanbaatar, 14192, Mongolia. ${ }^{5}$ Lomonosov Moscow State University, Faculty of Geography, Department of Biogeography, Leninskie Gory 1, 119992 Moscow, Russia.

* Corresponding author: amgalan69@yahoo.com

\title{
SOIL MICROBIAL CONTAMINATION AND ITS IMPACT ON CHILD DIARRHEAL DISEASE INCIDENCE IN ULAANBAATAR
}

\begin{abstract}
Air and soil contamination in developing countries exacerbates due to poor management of waste collection and serves as a morbidity and mortality factor. This study aimed to conduct an assessment of soil pollution level in Ulaanbaatar and establish a correlation between microbial contamination and registered occurrences of contagious diarrheal diseases among children ( $0-5$ years old). This is a cross-sectional study conducted in Ulaanbaatar in June-September of 2016. Samples of soil and contagious diarrheal disease morbidity data in 0-5-year-old children were used. Samples were taken from the sites three times, in July, August, and September. The data analysis was done in the SPSS-21 program and relevant parametric and non-parametric tests were used. The highest level microorganisms were found in the samples taken from sites near major markets and then in the samples from ger areas. The analysis of the samples revealed that 111.78 microorganisms exceed the standard level 1.1 times in summer. The Escherichia coli (E.Coli) and Proteus also contaminated the ground water. All diarrhea occasions in Ulaanbaatar were analyzed by seasons and months, the prevalence was peaking in August. A correlation was found with the soil E.Coli titers and infectious diarrheal disease children under five years old morbidity. The number of microorganisms in soil tends to increase in summer. Diarrheal disease infections among children under five increase most in summer and autumn and correlate with soil contamination with pathogenic microorganisms.
\end{abstract}


CITATION: Myagmardorj Oyunchimeg, Badrakh Burmaajav, Altangerel Enkhjargal, o Sambuu Tsegmed, Batbaatar Suvd, Otgonbyamba Oyun-Erdene, Davaadorj Zolzaya, Demberel Otgonbayar, Dovdon-Ulzii Oyunchimeg, Lkhagvasuren Azjargal, Ganchimeg Soyombo, Khishigt Byambasuren, Baldandorj Dorjkhand, Sandag Enkh-Amgalan, Svetlana M. Malkhazova, Byambaa Tsogtbaatar (2019) Soil Microbial Contamination And Its Impact On Child Diarrheal Disease Incidence In Ulaanbaatar. Geography, Environment, Sustainability, Vol.12, No 4, p. 243-251

DOI-10.24057/2071-9388-2019-104

\section{INTRODUCTION}

The United Nations defines soil as a basis for agricultural development, ecosystem services, and food security and highlights its importance for the sustainability of life on the planet. Moreover, the $68^{\text {th }}$ Session of the UN General Assembly announced the year of 2015 as an international year of soil (Gomiero 2016). Soil is considered a non-recoverable natural resource. Fertile soils play an essential role in the provision of livelihood and needs for millions of people and support food production, provide ecosystem services and regulate the climate (Stringer 2011).

Air and soil pollution in developing countries exacerbates because of poor management of waste collection, storage and processing, and serves as a morbidity and mortality factor.

Soil is a dynamic, natural body occurring on the surface of the Earth. It is a medium for plant growth. Soil pollution is defined as a phenomenon characterized by the loss of structural and biological properties by the soil layers as a result of numerous human and natural factors, such as wind, deforestation, chemical use, etc. Developmental activities such as construction, transportation and manufacturing not only deplete the natural resources but also produce large amount of waste that leads to pollution of air, water, soil, and oceans, global warming and acid rains (Gangadhar 2014). Soil pollution is a condition of excessive concentration of substances (fertilizers, pesticides, organic chemical compounds, acidic and alkali compounds) surpassing their normal level in nature negatively affecting the aqua systems, atmosphere, ecosystems, and organisms. Local soil contamination occurs where intensive industrial activities, inadequate waste disposal, mining, military activities or accidents have introduced excessive amounts of contaminants. Soils only have a limited ability to process these contaminants, through filtering or transformation, for example. Once this ability is exceeded, issues such as water pollution, human contact with polluted soil, plants taking up contaminants and dangers from landfill gases become more significant (Liedekerke et al 2014). Multiple kinds of research have confirmed that the main source of soil pollution in Ulaanbaatar is the pit latrines of the ger areas (Narantuya L et al 1991; Urantsetseg et al 2001). In 2013, the pathogenic microbial contamination of the soil in Ulaanbaatar reached a severe level for $20.6 \%$ of the territory of the city, medium level for $74.5 \%$ and at a mild level for only 5\% of the territory (CGA 2013).

According to the data of the National Statistics Office of Mongolia for 2015, Ulaanbaatar was inhabited by 1.4 million people and over $60 \%$ of them lived in ger districts. Moreover, $97.3 \%$ of all households in ger areas used pit latrines. The city also hosts 314 car repair shops, tire repair shops, car oil and spare parts sales points, 166 gas stations and oil storage facilities, 4 asphalt factories, 19 brick factories, 32 gravel extraction sites and 76 hides processing factories which also serve as factors negatively affecting the environment and population health (Government of Mongolia 2009).

According to the World Health Organization report, three million children dies every year due to diarrheal disease and most of 
them are children from the developing world. The occurrence of diarrhea among the general population not exclusively in ger district dwellers has been increasing recently presenting an issue of urgency to the health sector (Avaandorj 2014). Multiple studies of chemical and microbial contamination of the soil in Ulaanbaatar have been undertaken, however, a scarce amount of works devoted to exploring the soil pollution in ger districts is available (Kasimov et al 2011, 2016). Therefore, it is vitally important to study the chemical and microbial contamination level in ger areas (living area of the city which are not connected to the central heating and sewage system) of Ulaanbaatar hosting more than half of the population of Ulaanbaatar.

This study aims to conduct an assessment of soil microbial pollution levels in Ulaanbaatar and establish a correlation between such contamination and registered occurrences of contagious diarrheal diseases among children (0-5 years old).

\section{MATERIALS AND METHODS}

This is a cross-sectional study conducted in 9 districts of Ulaanbaatar in JuneSeptember, 2016. Samples for laboratory tests (microbiological) were collected from the soil at various locations and the data of contagious diarrheal disease morbidity of children under five years old in the 73 khoroos (the smallest unit of community in the city) adjacent to these locations were analyzed. For the study of the level of soil bacterial contamination, samples were taken from 111 sites in ger areas of 9 districts of Ulaanbaatar and 1 site was used for a reference site (Fig 1). Samples for microbiological tests were taken from the sites three times, in July, August, and September. The soil microbial contamination characteristics were studied in the laboratory of the National Centre for Public Health (MSO 2008).

Soil sampling area. The soil sampling was arranged in 9 districts of Ulaanbaatar with consideration of the areas of the ger suburbs. However, to improve the scope of the study and avoid sampling errors,

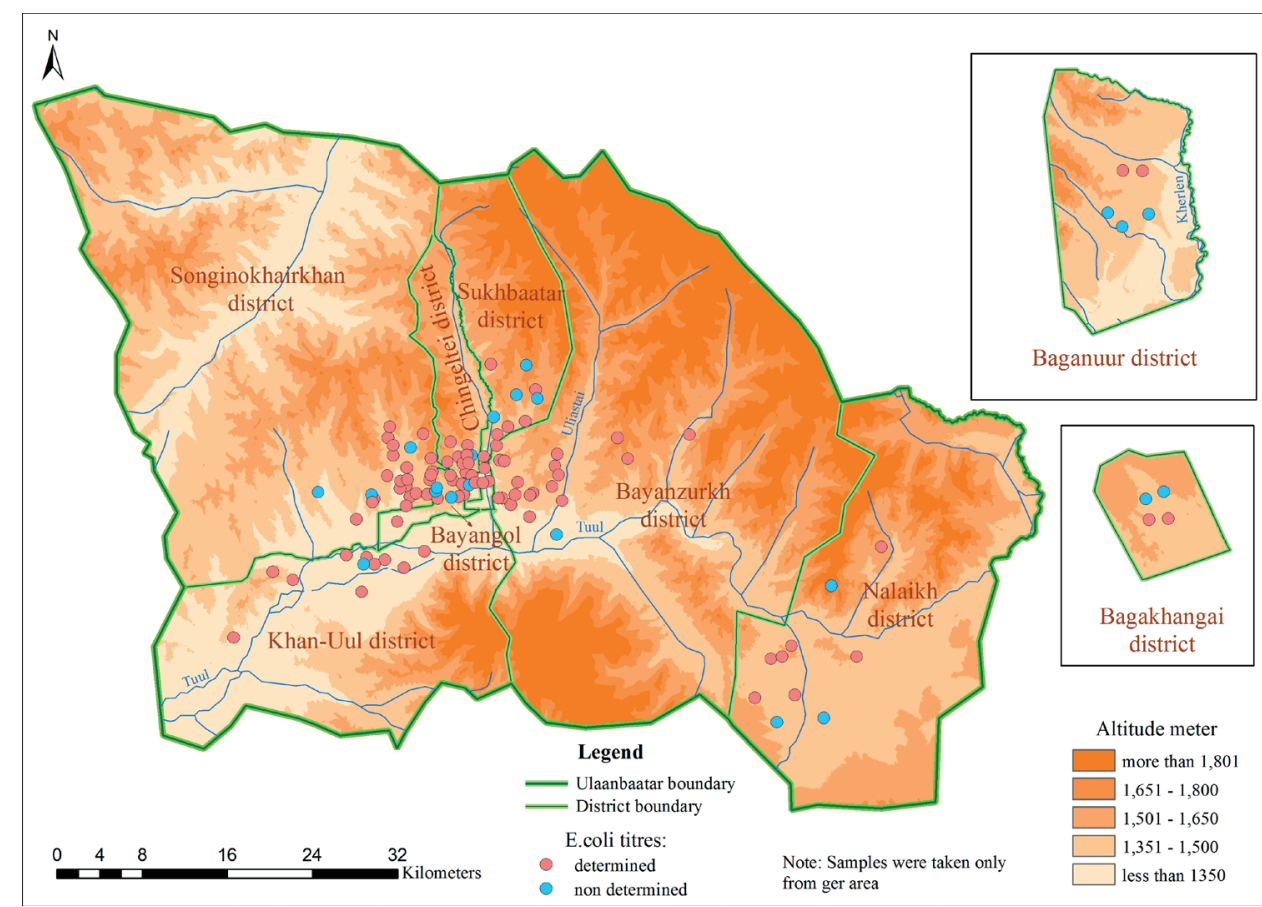

Fig. 1. Map of soil sampling location and existence of E.Coli titers by districts of Ulaanbaatar city 
we increased the number of sites and took samples from 111 sites. For identification of the sampling sites, the ger area of Ulaanbaatar was divided into 10 segments to pick up 10 sites from each segment. A site at a sufficient distance from sources of contamination was chosen as a reference site and the data of the analysis of the other samples were compared against it. Also, samples were taken from the drinking water sources in the vicinity of 20 $\mathrm{m}$ from the sampled sites to examine the transmission of contamination and assess their risk effects.

Soil sampling methodology. An "envelope" method was used to perform soil morphological recording in conformance with the documents: "Environmental preservation. General requirements for taking a sample for soil research MNS 32981990"; "Soil Procedures of taking samples; using containers and transporting MNS 2305-1994 in extracting the samples (MSO 1994)". According to the national standard, microbiological contamination was divided by "low degree"," "medium degree" and "high degree" contamination, based on titers of microorganisms.

Establishing effects of soil pollution on underground water. To establish whether the soil pollution affects the underground water, samples of water were taken from the underground water from the proximity of the soil sampling sites. 20 water points were selected and 60 samples were taken in three repetitions. Tests for contamination with pathogenic bacteria were done at the reference laboratory of the National Public Health Centre.

Diarrheal disease. We had a diarrheal disease record of children under four years old from the National center for Combinable disease of Ulaanbaatar city. Those are the whole year record of all diarrheal disease records of 2016. For the correlation between soil contamination and diarrheal disease, we selected the incidence of the outbreak during the data collection period (July-September, 2016).
Statistical analysis. For the quantitative data analysis, we used Statistical Package for the Social Sciences-21 (SPSS-21). The relevant parametric and non-parametric tests were used for calculation. For testing the differences of the results, appropriate nonparametric tests were used: Kruskal-Wallis one way analysis of variance, Mann-Whitney $\mathrm{U}$ test and paired T-tests. The KolmogorovSmirnoff test has been used to check the normality of data distribution. Pearson's correlation coefficient also has been used and linear regression was calculated for estimating soil microbiological influence on diarrheal diseases.

\section{RESULTS}

The morphological study of the selected sites showed that $29.4 \%$ of the ger area soil near service centers has brown colored soil, $10.3 \%$ has the color of black one, $52.9 \%$ features high density, $72.1 \%$ is sand-rock and $70 \%$ has been severely eroded. 80\% of the brown soils were around the service centers in the ger areas. The morphological records of the soil sampled near car and bike repairs, and car washing services showed that $35.7 \%$ of the soil is light brown, $64.3 \%$ has high density, and $71.4 \%$ is heavily eroded. At the sample sites, 31.5\% of the soil was light brown, $70.8 \%$ has sand-rock mechanic structure, and 53.9\% has high density. The percentage of soil humus was 7.89 at the reference site. The average percentage of humus compared with the reference site was 1.80 times lower.

Soil bacterial contamination level is defined as the total number of microbes, titers of E.coli, Proteusand bacteria, Clostridium Perfringens and thermophilic bacteria per 1 gram of soil.

The number of microbes in the soil of the ger areas in Ulaanbaatar was high at all sites in July-September. Microbes increase trend was observed during the summer months. The level of microbiological titers of samples taken in September was twice as higher (42.56\% [95\%Cl 31.74-60.1]) than the July samples (21.51\% [95\%Cl 16.56-27.53]), and 1.3 times higher than the August samples $(p=0.003)$. 
In categorizing the sample sites by locations, as shops, hair stylists locations, bathhouses, schools and kindergartens, major market places were defined as service centers (Fig 2).

The number of microorganisms from sample location sites showed the highest level in the samples taken from sites near major markets amounting to 37.63 million organisms, then in the samples from ger areas amounting to 37.24 million and in the samples taken near service centers.

Titration of E.Coli. Detection of E.Coli titers in any laboratory test indicates comparatively fresh contamination with human or animal feces. Titer corresponds to the least amount of soil expressed in grams in which the microorganisms are still found. Of the total 333 soil samples, $85.3 \%$ (284) were yielded by E.Coli titers while $14.7 \%$ (49) were clean. Most $79.2 \%$ (225) of the sites where E.Coli titers were detected had a low degree of contamination, $18.3 \%$ (52) had a medium degree and $2.1 \%$ (7) had a high degree of contamination.

Proteus. It does not serve as a soil contamination indicator but it is positive along with E.Coli while Clostridium perfringens indicates contamination. The average content of Proteus bacteria in July, August, and September in the ger areas soil samples was highest amongst the other locations and fit in the high contamination degree of the standard. The contamination degree was medium (100-1000) in the samples from major market areas, roads, and gas stations. Proteus was detected in $65.1 \%$ (217) of all samples of which $38.1 \%$ had a low degree, $22.5 \%$ (75) had a medium degree and $4.5 \%$ (15) had a high degree of contamination.

C.Perfringens titers. The soil analysis was negative for C.Perfringens titers in the samples from Bayangol, Khan-Uul, Nalaikh, Baganuur, and Bagakhangai districts. It was positive in Songinokhairhan (14.7\%) and Bayanzurh (11.7\%) districts in the category of low degree of contamination.

Soil and water contamination. To confirm whether soil contamination affects underground water, water samples were taken from the household yards adjacent to the soil sampling sites and from households that have deep wells in those areas. The analysis of the samples revealed that 111.78 microorganisms exceeding the standard level 1.1 times in summer. The presence of E.Coli and Proteus in summer and autumn confirms that the water is contaminated. Microbial contamination is 1.56 times higher in autumn than in summer and $\mathrm{E}$. coli titers are 1.3 times more in autumn $(T=4.6, p=0.004)$. Among all water samples used in the course of the study, $47.8 \%$ (27) contained more than 100 microorganisms while E.Coli was detected in $24.7 \%$ (17) and Proteus was detected in $27.5 \%$ (19) of the samples (Table 1).

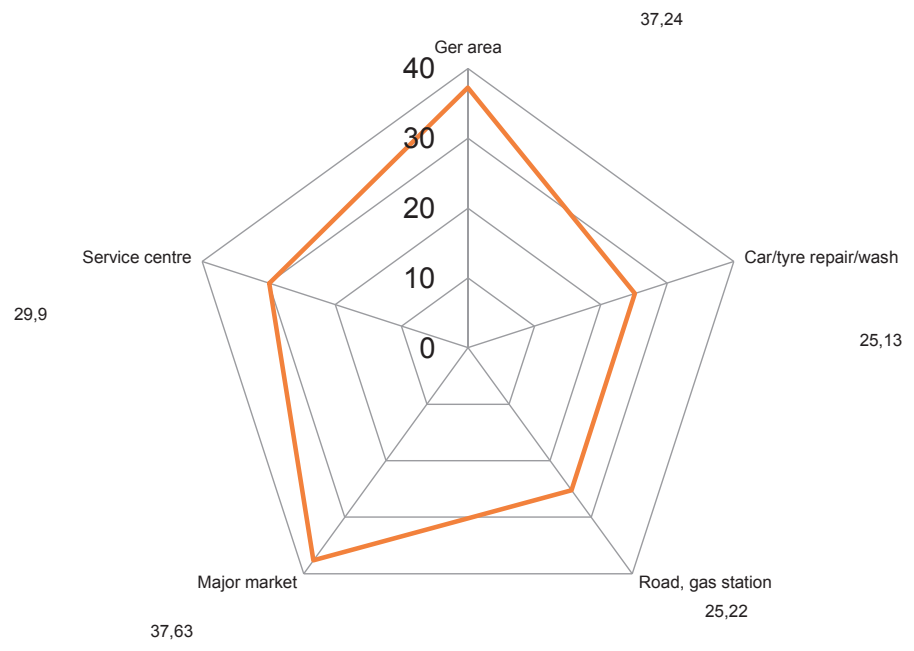

Fig. 2. Average microbial level in Ulaanbaatar, July-September 2016 
Table 1. Microbial contamination of the soil and water by seasons

\begin{tabular}{|c|c|c|c|c|c|c|c|c|c|}
\hline \multirow{2}{*}{ Indicators } & \multirow{2}{*}{$\mathrm{N}$} & \multicolumn{2}{|c|}{ Summer } & \multirow{2}{*}{$\mathrm{N}$} & \multicolumn{2}{|c|}{ Autumn } & \multirow{2}{*}{$\mathrm{N}$} & \multicolumn{2}{|c|}{ Total } \\
\hline & & Mean & $95 \% \mathrm{Cl}$ & & Mean & $95 \% \mathrm{Cl}$ & & Mean & $95 \% \mathrm{Cl}$ \\
\hline \multicolumn{10}{|c|}{ Soil microbial indicators } \\
\hline $\begin{array}{l}\text { Microorganisms } \\
(\mathrm{m} / \mathrm{n})\end{array}$ & 222 & 27.25 & $\begin{array}{l}21.76- \\
34.16\end{array}$ & 111 & 42.56 & $\begin{array}{l}29.53- \\
55.49\end{array}$ & 333 & 32.35 & $\begin{array}{l}26.44- \\
39.04\end{array}$ \\
\hline E.Coli & 222 & 370.41 & $\begin{array}{c}205.97- \\
529.1\end{array}$ & 111 & 488.83 & $\begin{array}{c}225.75- \\
820.07\end{array}$ & 333 & 409.88 & $\begin{array}{r}281.32- \\
575.63\end{array}$ \\
\hline Proteus & 222 & 702.52 & $\begin{array}{l}453.7- \\
1012.9\end{array}$ & 111 & 719.37 & $\begin{array}{l}348.12- \\
1205.43\end{array}$ & 333 & 708.14 & $\begin{array}{l}493.21- \\
961.10\end{array}$ \\
\hline Perfringens & 222 & 10.36 & $\begin{array}{l}6.9- \\
14.05\end{array}$ & 111 & 757 & $\begin{array}{l}3.93- \\
11.75\end{array}$ & 333 & 9.43 & $\begin{array}{l}6.72- \\
12.13\end{array}$ \\
\hline \multicolumn{10}{|c|}{ Microbial indicators of water } \\
\hline Microorganisms & 19 & 111.78 & $\begin{array}{l}102.5- \\
121.49\end{array}$ & 9 & 95.1 & $\begin{array}{l}85.95- \\
55.49\end{array}$ & 28 & 32.35 & $\begin{array}{l}26.44- \\
39.04\end{array}$ \\
\hline E.Coli & 19 & 346.32 & $\begin{array}{c}166.54- \\
576.6\end{array}$ & 9 & 30 & $10-55$ & 28 & 244.64 & $\begin{array}{l}104.38- \\
420.27\end{array}$ \\
\hline Proteus & 18 & 270.0 & $\begin{array}{l}110.0- \\
447.32\end{array}$ & 7 & 74.29 & $\begin{array}{c}33.66- \\
100\end{array}$ & 25 & 215.20 & $\begin{array}{c}100- \\
359.2\end{array}$ \\
\hline
\end{tabular}

We calculated the number of microorganisms in the soil, where E.Coli, Proteus, Enterococci, anaerobic microorganisms, Perfringens and Salmonella serve as indicators of soil microbial contamination against the number of microorganisms in the water samples from adjacent underground water sources, and the E.Coli, Proteus, Enterococci, anaerobic microorganisms, perfringens and salmonella correlation using the Spearman correlation coefficient was applied. The total number of microorganisms is in a positive weak correlation with soil E.Coli $(r=0.252, p=0.019)$ and also in a positive weak correlation with soil proteus $(r=0.266, p=0.013)$. The water E.coli titers are positively medium correlated with the soil Clostridium Perfringers ( $r=0.544$, $p=0.003)$ and salmonella ( $r=0.398, p=0.03)$ level. The water Proteus level had a strong positive correlation with the soil nitrates level $\left(\mathrm{NO}_{3}\right)(r=0.717, \mathrm{p}=0.45)$.

Sources and factors of soil pollution. The effect of the ger area households, solid and liquid waste disposed in ravines by the households, their latrines, the number of latrines in the area of the sampling site, their distance, bus stations, service centers, and others on soil pollution was also computed. There is a weak correlation of the presence of roads in the ger areas with the number of soil microorganisms and medium correlation with water Proteus ( $r=0.546, p=0.005)$, and a weak correlation of the number of latrines at soil sampling sites with E.Coli titers $(r=0.133$, $p=0.01)$ and Proteus $(r=0.124, p=0.02)$. The correlation between soil E.Coli titers and water microorganism population numbers is weak and direct $(r=0.252, p=0.01)$. The number of soil microorganisms is in direct but weak correlation with the distance to a pit latrine of the sampling site $(r=0.1, p=0.05)$.

Soil contamination and diarrheal diseases in children under five years old. Among the population of Ulaanbaatar, 4023 occurrences of contagious diarrheal diseases were registered in 2016 indicating an increase by 181 against the previous year. There are 2336 occurrences of dysentery or the rate of 18.1 per 10,000 population which shows an increase by 2.7 compared with the previous year. 
As of the cases of dysentery infections analyzed by the sources, $7.4 \%$ are from sick persons, $0.1 \%$ are from asymptomatic carriers and $92.5 \%$ are from unknown sources. As for the routes of infection, 10.2\% are via domestic contacts while $89.8 \%$ are via unknown routes $(\mathrm{MOH} 2016)$.

In a whole year, the occurrence of intestinal infections (AO2-AO5) in January-December 2016 analyzed by districts reveals the diarrheal diseases prevalence in two districts of Ulaanbaatar city - the occurrence in Bayazurkh and Chingeltei is higher than in the other 7 districts. The pick of diarrheal disease incidences in Ulaanbaatar was during August and September which was in line with the soil data collection period. The tendency of diarrheal disease infections in the population and underfive years old children in the khoroos in the ger areas of the city exhibit increase from June reaching the highest number of registered cases in September. A correlation was found in which an increase in the soil E.Coli titers is accompanied by an increase in the infectious diarrheal disease morbidity in children under five per 10,000 children. Regression analysis demonstrated that 1\% of the causes of infectious diarrheal disease morbidity of considered children are due to the number of E.Coli in the surface soil, and $2.1 \%$ of them were caused by all number of bacteria in surface soil.

\section{DISCUSSION}

The current research was undertaken in the ger areas of nine districts of Ulaanbaatar in June-September 2016. We performed the tests of soil microbial tests (total number of microorganisms (per 1 gram), intestinal pathogens (per 100 ml), ClostridiumPerfringers titers, E.Coli, anaerobic microorganisms) in corresponding laboratories and assessed the pollution and contamination situations. Also, we established the effect of soil microbial contamination on the prevalence of diarrheal disease infections among children under 5 years old registered at the khoroo health centers adjacent to the soil sampling sites.
Study of 2001 "Hygiene assessment of the soil microbial contamination and chemical pollution level in Ulaanbaatar" established that the city's soil microbiological contamination was at the III degree (Public Health Institute 2001). Research on the "Soil microbiological contamination level in major cities" of 2005 found the content of lead exceeding the maximum permissible level 2.4-2.8 times. This study also established that the level of microbiological contamination of the city is as the III degree as the preceding studies. Public Health Institute (2001, 2009) "Soil microbiological study of in cities" showed soil E.Coli titers as 0.004 on average, anaerobic titers as 0.001 and the number of thermophilic bacteria as $28.8 \times 103$ cells $/ \mathrm{g}$. A study of 2010 in Ulaanbaatar found that soil microbiological contamination was 10 16 times higher than the permissible level. And another survey finding of 2011 defined that Ulaanbaatar soil had a high level of fungi content besides pathogens such as E.coli and Salmonella. Also, Batkhishig et al has found that $31 \%$ of soil in Ulaanbaatar had a high degree of contamination, $45.5 \%$ had medium and $23.5 \%$ had a low degree of contamination of E.Coli titers (Batkhishig et al 2016).

The results of our research confirm the outcomes of the above studies. The number of microorganisms in July-September was at a contaminated level at all sites selected for the study. A tendency for an increase in several microbes was observed during the months when the samples were taken with a twice higher degree in September against July, 1.3 times against August. However, it is notable that microbial contamination was highest in the samples taken near major markets, ger areas and service centers.

Detection of E.Coli titers in any laboratory test indicates comparatively fresh contamination with human or animal feces. The findings of our study demonstrate that the surface soil in the ger areas has continually been contaminated with human and animal feces. Contamination at levels higher than the medium degree is found in 20\% of the contaminated soil samples. These are observed at sites near pit latrines in the ger areas. 
Drinking water standard Mongolian National 음 Standard 900:2005 provides that the total number of microorganisms in drinking water should be less than 100 and there should be no E.Coli and other pathogenic bacteria. To study the effect of soil contamination on underground water, samples were taken from households that have deep wells in their yards and the analyses revealed that the number of microorganisms in the water increased 1.1 times in summer. The detection of E.Coli and Proteus indicates that the water is contaminated.

The main point is that E.Coli titers are in direct correlation with the numbers of microorganisms and Salmonella in water. The correlation between E.Coli titers and water microorganism quantities is also indicating that soil contamination directly affects the safety of underground water. Besides, there is a strong correlation between the number of pit latrines in the proximity of the soil sampling site and soil E.Coli and Proteus.

Soil contamination and morbidity. In total, 4023 intestinal infections cases were registered among a population of Ulaanbaatar in 2015, an increase of 181 cases compared with the previous year. In these cases, 58.1\% were dysentery, 9.4\% were food poisoning, $2.6 \%$ salmonellosis and 29.9\% were hand foot and mouth diseases. The dynamics of diarrheal disease infections among a population of the khoroos in the ger areas of Ulaanbaatar, especially children under five years old, showed an increase starting in June and reaching its peak in September with the registration of the highest number of cases. According to the regression analysis, about $1 \%$ of the causes of infectious diarrheal disease children morbidity in the ger areas could be caused by E.Coli in the surface soil pollution and 2.1\% of them are caused by all bacteriological contamination of the soil.

\section{CONCLUSION}

The number of microorganisms in the ger area soil in Ulaanbaatar is high in JulySeptember indicating severe contamination. The number of microorganisms in soil tends to increase in summer. Major markets, pit latrines in the ger areas and the major service centers are the direct sources of microbiological contamination. The surface soil in the ger areas of Ulaanbaatar is polluted with human and animal feces, and the influence of substandard pit latrines further leads to contamination of the underground water with pathogenic microorganisms. Diarrheal disease infections in the population of the khoroos of the ger areas of Ulaanbaatar, especially children under five years old, increase most in summer and autumn. Soil contamination with pathogenic microorganisms directly affects the occurrence of intestinal diseases in children of the ger areas of Ulaanbaatar.

\section{REFERENCES}

Avaandorj D. (2014). Some geoecological issues in Mongolia, Ulaanbaatar. Soil Science, 376-383.

Batkhishig O., Oyunbat P., Bolormaa Ts. (2016). Microbiological contamination of soil in Ulaanbaatar. In: Discussion book on soil protection and reduction of land degradation, Ulaanbaatar, Institute of Geography and Geoecology, 265-282.

Gangadhar Z. (2014). Environmental Impact Assessment on Soil Pollution Issue about Human Health. Int. Res. J. Environment Sci. International Science, Vol. 3(11), 78-81.

CGA. (2013). Amendments to the General Plan of Development of Ulaanbaatar till 2020, Development tendency till 2030, Study of the current situation in Ulaanbaatar, 1, 21-24.

Government of Mongolia (2009). Millennium Development Goals of Ulaanbaatar, Ulaanbaatar. 
Gomiero (2016). Soil Degradation, Land Scarcity, and Food Security: Reviewing a Complex Challenge.

Kasimov N., Kosheleva N. E., Sorokina O. I., Bazha S.N., Gunin P. D., and Enkh-Amgalan S. (2011). Ecological-geochemical state of soils in Ulaanbaatar (Mongolia). Eurasian Soil Science, 44 (7), 709-721, DOI 10.1134/S106422931107009X

Kasimov N., Kosheleva N., Gunin P., Korlyakov I., Sorokina O., and Timofeev I. (2016). State of the environment of urban and mining areas in the Selenga transboundary river basin (Mongolia Russia) // Environmental Earth Sciences, 75(1283), 1-20, DOI 10.1007/s126650166088-1

Liedekerke M., Prokop G., Rabl-Berger S., Kibblewhite M. and Louwagie G. (2014). Progress in the management of Contaminated Sites in Europe. Luxembourg: Publications Office of the European Union. DOI:10.2788/4658

MSO. (2008). Soil quality. Highest permissible levels of soil contaminating substances and elements. MNS 5850:2008, Ulaanbaatar, 4-5.

MSO. (1994). MNS 3298-1990" and "Soil Procedures of taking samples; use containers and transporting MNS 2305-1994, 1-7.

MOH, CHD, (2016). Communicable diseases, In: Health indicators, 2016. Ulaanbaatar: Center for Health Development, 60-67.

Narantuya L., B. Burmaa, S. Bumaa, J. Kupul, Sh. Uranstegeg (1991). Content of heavy metals in the surface soil of Ulaanbaatar, mapping of the sources of pollution, Study report, National Center for Public Health.

Public Health Institute (2001). "Soil microbiological contamination level in major cities", Study report, Public Health Institute, Ulaanbaatar.

Public Health Institute (2009). Soil microbiological study in major cities, survey report, Ulaanbaatar, Study report, Public Health Institute, Ulaanbaatar.

Stringer Lindsay C. (2011). Global land and soil degradation: challenges to soil Sustainability Research Institute, School of Earth and Environment, University of Leeds, Survey report, West Yorkshire, UK.

Urantsetseg Sh., B.Burmaa., S.Bumaa., J.Kupul. (2001). The level of soil microbiological contamination and chemical pollution in Ulaanbaatar and hygiene assessment, Survey report, Ulaanbaatar. 